\title{
A Proteção ao Consumidor no Sistema Jurídico Brasileiro*
}

\section{Sálvio de Figueiredo Teixeira"}

\section{SUMÁRIO}

1. Razões e antecedentes históricos

2. O sistema normativo brasileiro de proteção ao consumidor

2.1. Constituição de 1988

2.2. O Código de Defesa do Consumidor
a) Codificação
b) Influência estrangeira
c) Estrutura do Código de Defesa do Consumidor

3. As principais inovações do sistema brasileiro de proteção ao consumidor

4. A proteção contratual e o direito privado

5. A desconsideração da personalidade jurídica

6. As ações coletivas e a defesa do consumidor em juízo

7. A inversão do ônus da prova

8. A legitimação ativa nas ações coletivas

9. Conclusão

10. Razões e antecedentes históricos

A Revolução Industrial, como de resto as revoluções do fim do século XVIII, modificaram substancialmente as relaçóes políticas, sociais e econômicas, culminando também no surgimento de uma nova categoria de indivíduos, os consumidores, que passaram a sentir os efeitos da produção em série e da ampliação das atividades empresariais e comerciais. Desde essa época, há mais de duzentos anos, portanto, os participantes da chamada sociedade de consumo (mass consumption societyou Konsumgesellschaft) passaram a ter alteraçóes em sua vida cotidiana, sob o influxo das demandas econômicas.

ODireito, em sua perspectiva de acompanhar os fenômenos sociais, aqui recordado o aforisma latino ius oritur factum, há muito protege o consumidor, em suas vestes de comprador, locatário de bens e serviços, passageiro de transporte, segurado etc. Embora

1 "O direito do consumidor", in Revista dos Tribunais, n. 670, ago 1991, p. 50. 
sem um tratamento sistematizado, é de longa data a disciplina legal, doutrinária e jurisprudencial dos direitos dessas categorias, como exemplificam os códigos civis dos Países do tronco romano-germânico, vinculados à vertente do Civil Law.

A última metade do século XX, todavia, assistiu ao crescente avanço da indústria e do comércio, notadamente após a Segunda Guerra Mundial, a partir de quando os mercados se ampliaram para atingir a circulação universal da riqueza.

Nos últimos cinqüenta anos, a par do surgimento dos blocos econômicos comunitários, entre os quais se destaca a União Européia, assistimos ao agigantamento dos grupos econômicos e empresariais e à concentração da produção em empresas em variados setores. E no crepúsculo do século passado, o fenômeno da globalização possibilitou ainda mais que os fornecedores de produtos e de serviços se unissem em corporaçóes internacionais de grande porte. Enquanto isso, do outro lado, permaneciam os "consumidores" em sua esfera individual, como destinatários finais dessa produção.

Neste contexto, a sistematização do Direito do Consumidor surgiu como resposta da ciência jurídica ao abismo entre as poderosas redes de fornecedores e os milhões de consumidores, que se viam afastados da efetiva proteção de seus direitos. Percebeu-se, enfim, a insuficiência da concepção liberal individualista para satisfazer essa nova realidade da sociedade de consumo. A respeito, com aguçado espírito crítico, observou KONDER COMPARATO, muito antes da disciplina dogmática da matéria, ainda em 1974:

"A idéia de uma sistemática proteção do consumidor, nas relações de mercado, é sem dúvida estranha à teoria econômica clássica. Esta partia, com efeito, da noção de necessidade econômica individual, imaginando que ela se exprimisse livremente no mundo das trocas, como imposição da própria natureza, e como elemento formador da demanda global, à qual adaptar-se-ia, ex post factum, a oferta global. Nessa concepção, não cabe pois falar em proteção do consumidor, pois entende-se que é este, afinal de contas, quem dita as leis do mercado. Toda a discussão cinge-se ao aspecto da capacidade econômica de consumo, ou seja, a aptidão do consumidor a pagar o preço dos bens e serviços de que necessita" (A proteção do consumidor: importante capítulo do Direito Econômico, in Revista de Direito Mercantil, Industrial, Econômico e Financeiro, ano XIII, n. 15/16, 1974).

Os avanços no tema partiram, ultima ratio, de uma constatação manifesta, a vulnerabilidade do consumidor, que mais e mais se enfraquecia no plano individual, $\mathrm{e}$ visaram, na outra ponta, a um objetivo consensualmente admitido, a imprescindibilidade da defesa desse consumidor.

O Direito deparou, então, com duas situaçóes aparentemente antagônicas:

De um lado, preservar as leis de mercado e o desenvolvimento econômico, que se ancoraram na globalização como expressão da ordem capitalista;

De outro, evitar o esmagamento dos indivíduos pelas corporaçóes.

A solução mediadora adotada conferiu ao Direito do Consumidor um caráter de intervenção estatal no mercado, hoje presente tanto nos países do Common Law quanto 
do Civil Law, a exemplo do que ocorre na Europa continental e nos sistemas que lhe seguiram o modelo, entre eles o brasileiro.

Além desse intervencionismo estatal, o Direito do Consumidor reflete outra tendência contemporânea da ciência jurídica em todos os seus ramos, a saber, garantir a efetividade do acesso à Justiça e aos direitos proclamados no ordenamento jurídico.

Os séculos XIX e XX, até a Segunda Grande Guerra, revelaram a fragilidade dos direitos declarados formalmente na Constituição e nas leis ordinárias em garantir os indivíduos e as células sociais contra o arbítrio e os excessos e abusos dos grupos políticos e econômicos. As sociedades passaram a preocupar-se com os instrumentos para assegurar a inclusão de cada um e de todos como protegidos pela ordem jurídica, como aplicação do princípio democrático. O Direito do Consumidor inseriu-se nesse panorama, como registrou ANTÔNIO HERMAN BENJAMIN:

"Quanto maior for o número dos vulneráveis, maior será a sensibilidade estatal.É que em uma sociedade democrática, compreensivelmente, a equação numérica tem enorme peso. Esta a razáo para que o Direito, muitas vezes, fique ao lado da maioria mesmo que com a minoria esteja o poder e a riqueza. Daí que o Direito do Consumidor não se justifica apenas como produto da sensibilidade do legislador para com a vulnerabilidade do consumidor. Igualmente relevante no seu desenvolvimento é o fato de que os consumidores são imensamente majoritários no mercado"1.

A fim de atingir esse duplo propósito, proteger a parte mais frágil nas relações econômicas e jurídicas e a ela assegurar o acesso à Justiça, o Direito do Consumidor se bifurcou em normas de direito material e normas de direito processual, ora para equilibrar o vínculo entre as partes, ora para moldar os institutos processuais à defesa individual e coletiva dos direitos.

2. O sistema normativo brasileiro de proteção ao consumidor

\subsection{Constituição de 1988}

A analítica Constituição brasileira de 1988, na procura de ampliar e reforçar os direitos e interesses individuais e coletivos, alçou à categoria e nobreza dos direitos fundamentais a defesa do consumidor e a incluiu entre os princípios da ordem econômica nos seus arts. 5, XXXII, e 170, V, assim redigidos:

. "Art. 5"

$[\ldots]$

XXXII - o Estado promoverá, na forma da lei, a defesa do consumidor”.

"Ministro do Superior Tribunal de Justiça. Membro da Academia Brasileira de Letras Jurídicas. 
. "Art. 170. A ordem econômica, fundada na valorização do trabalho humano e na livre iniciativa, tem por fim assegurar a todos existência digna, conforme os ditames da justiça social, observados os seguintes princípios:

[...]

$\mathrm{V}$ - defesa do consumidor".

A Constituição Federal, além de disciplinar a iniciativa legislativa na matéria, na órbita dos tributos também estabeleceu, no art. $150, \S 5^{\circ}$, que "a lei determinará medidas para que os consumidores sejam esclarecidos acerca dos impostos que incidam sobre mercadorias e serviços". E, em relação à prestação de serviços públicos, diretamente ou por concessão e permissáo, o seu art. 175 atribuiu à lei ordinária dispor sobre os "direitos dos usuários".

O Ato das Disposiçōes Constitucionais Transitórias, por sua vez, em meio às normas de aplicação da nova Constituição e de transição entre o regime anterior e o atual, determinou que o Congresso Nacional elaborasse "código de defesa do consumidor".

Como se vê, a opção do constituinte originário se evidenciou em vários dispositivos do texto constitucional em favor da defesa do consumidor, impondo ao legislador ordinário a tarefa de tornar efetivo esse propósito.

\subsection{O Código de Defesa do Consumidor}

a) Codificação

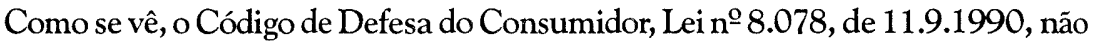
se originou, como na França, de uma simples decisão ministerial, tendo encontrado sustentação, ao contrário, na própria Constituição. Por outro lado, a opção do constituinte de 1988 por um código, e não por uma lei, contribuiu para dar coerência e homogeneidade a esse novo ramo do direito, além de fortalecer o tratamento da matéria.

A propósito, quando do debate durante os trabalhos preparatórios de elaboração do Código, assinalou a doutrina:

"O constituinte, claramente, adotou a concepção da codificação, nos passos da melhor doutrina estrangeira, admitindo a necessidade da promulgação de um arcabouço geral para o regramento do mercado de consumo.

Ora, se a Constituição optou por um Código, é exatamente o que temos hoje. A dissimulação daquilo que era código em lei foi meramente cosmética e circunstancial.É que, na tramitação do Código, o lobby dos empresários, notadamente o da construção civil, dos consórcios e dos supermercados, prevendo sua derrota nos plenários das duas Casas, buscou, através de uma manobra procedimental, impedir a votação do texto ainda naquela legislatura, sob o argumento de que, por se tratar de Código, necessário era respeitar um iter legislativo extremamente formal, o que, naquele caso, não tinha sido 
observado. A artimanha foi superada rapidamente com o contra-argumento de que aquilo que a Constituição chamava de Código assim não o era"2.

b) Influência estrangeira

Sem embargo da controvérsia inicial sobre a codificação, inspirou-se o Código de Defesa do Consumidor em modelos legislativos vigentes no estrangeiro. Com efeito, desde a Resolução n. 39/248, 9/4/1985, da Assembléia-Geral da Organização das Nações Unidas, identificada como a origem dos direitos básicos do consumidor, além da legislação comunitária européia as legislaçōes francesa, espanhola, portuguesa, alemã, mexicana, canadense e norte-americana foram as fontes de inspiração para o Código brasileiro. Como anota a mesma fonte doutrinária,

"A maior influência sofrida pelo Código veio, sem dúvida, do Projet de Code de la Consommation, redigido sob a presidência do professor Jean Calais-Auloy. Também importantes no processo de elaboração foram as leis gerais da Espanha (Ley General para la Defensa de los Consumidores y Usuarios, Lei n. 26/1984), de Portugal (Lei n. 29/81, de 22 de agosto), do México (Lei Federal de Protección al Consumidor, de 5 de fevereiro de 1976) e de Quebec (Loi sur la Protection du Consommateur, promulgada em 1979).

Visto agora pelo prisma mais específico de algumas de suas matérias, o Código buscou inspiração, fundamentalmente, no direito comunitário europeu: as Diretivas 84/ 450 (publicidade) e 85/374 (responsabilidade civil pelos acidentes de consumo). Foram utilizadas, igualmente, na formulação do traçado legal para o controle das cláusulas gerais de contratação, as legislações de Portugal (Decreto-Lei n. 446/85, de 25 de outubro) e Alemanha (Gesetz zur Regelung des Rechts der Allgemeinen Geschaftsbedingungen-AGB Gesetz, de 9 de dezembro de 1976).

Uma palavra à parte merece a influição do direito norte-americano. Foi ela dupla. Indiretamente, ao se usarem as regras européias mais modernas de tutela do consumidor, todas inspiradas nos cases e statutes americanos. Diretamente, através da análise atenta do sistema legal de proteção ao consumidor nos Estados Unidos. Aqui foram úteis, em particular, o Federal Trade Commission Act, o Consumer Product Safety Act, o Truth in Lending Act, o Fair Credit Reporting Act e o Fair Debt Collection Practices Act"3.

Essa influência da legislação estrangeira, contudo, não impediu a elaboração de um Código adaptado à realidade brasileira e às suas peculiaridades, em que sobreleva a desigualdade entre os mais abastados e os menos favorecidos, a acentuar a impotência e a hipossuficiência destes e a exigir do Direito, em conseqüência, respostas cada vez mais eficazes para ampliar o acesso à Justiça.

\footnotetext{
${ }^{2}$ Ada Pellegrini Grinover e Antônio Herman de Vasconcellos e Benjamin, "Código brasileiro de defesa do consumidor", 5a ed., Rio de Janeiro: Forense Universitária, 1997, p. 9.

${ }^{3}$ Op. cit., p. 10.
} 
c) Estrutura do Código de Defesa do Consumidor

A Lei n. 8.078, publicada em 12/9/1990, resultou de quase dois anos de elaboração legislativa, em cujo período o anteprojeto inicial, depois de intensos debates nas duas Casas do Congresso e audiências públicas, sofreu modificaçóes e aperfeiçoamentos proporcionados pela participação de importantes segmentos da sociedade, como indústria, comércio, serviços, governo, consumidores, cidadãos, além da contribuição de juristas e especialistas de reconhecida postura cultural.

O Código de Defesa do Consumidor conta com seis títulos, que tratam (a) dos direitos do consumidor, (b) das infrações penais, (c) da defesa do consumidor em juízo, (d) do sistema nacional de defesa do consumidor, (e) da convenção coletiva de consumo e (f) das disposiçóes finais.

O título I contém sete capítulos, iniciando pelas disposições gerais (I) e abordando a política nacional das relações de consumo (II), os direitos básicos do consumidor (III), a qualidade dos produtos e serviços, a prevenção e reparação dos danos (IV), as práticas comerciais, como a oferta, a publicidade e os abusos (V), a proteção contratual (VI) e as sanções administrativas (VII).

O título II cuida especificamente das infrações penais. E o título III, com importantes inovações também no campo processual, sobretudo nas áreas da legitimação das partes e dos efeitos da res iudicata, abrange, em quatro capítulos distintos, depois das disposições gerais, as ações coletivas para a defesa de interesses individuais homogêneos, as ações de responsabilidade do fornecedor e a coisa julgada.

O título IV, por sua vez, trata do sistema nacional de defesa do consumidor, enquanto o título V se ocupa da convenção coletiva de consumo e o último, o VI, se reserva às disposições finais.

3. As principais inovações do sistema brasileiro de proteção do consumidor

Importantes inovaçōes e peculiaridades extraem-se dessa sistematização, sendo de notar-se de início a coexistência de normas de direito material e normas de direito processual, assim como relevantes alterações na relação entre o direito público e o privado, tornando expressa a intervenção estatal na autonomia da vontade e na liberdade de mercado, princípios reitores do direito privado desde a construção do pacta sunt servanda.

Entre as suas principais inovaçōes, salienta a doutrina:

“- formulação de um conceito amplo de fornecedor, incluindo, a um só tempo, todos os agentes econômicos que atuam, direta ou indiretamente, no mercado de consumo, abrangendo inclusive as operações de crédito e securitárias;

- um elenco de direitos básicos dos consumidores e instrumentos de implementação;

- proteção contra todos os desvios de quantidade e qualidade(vícios de qualidade por insegurança e vícios de qualidade por inadequação);

- melhoria do regime jurídico dos prazos prescricionais e decadenciais; 
- ampliação das hipóteses de desconsideração da personalidade jurídica das sociedades;

- regramento do marketing(oferta e publicidade);

- controle das práticas e cláusulas abusivas, bancos de dados e cobrança de dívidas de consumo;

- introdução de um sistema sancionatório administrativo e penal;

- facilitação do acesso à Justiça para o consumidor;

- incentivo à composição privada entre consumidores e fornecedores, notadamente com a previsão de convenções coletivas de consumo"4.

Entre tantas, algumas merecem especial destaque, como se procurará demonstrar a seguir.

4. A proteção contratual e o direito privado

Ao proteger os contratos contra os abưsos dos agentes econômicos, o Código permitiu a intervenção dos órgãos de proteção ao consumidor, notadamente do Judiciário, nas cláusulas pactuadas entre as partes e também nos contratos de adesão, interferindo diretamente na autonomia da vontade para cercear as condiçóes que restrinjam as informaçōes ao consumidor e para caracterizar como "nulas de pleno direito" as cláusulas viciadas introduzidas nos contratos pelos fornecedores de produtos e serviços.

O Direito do Consumidor incorporou, na verdade, o dirigismo contratual característico das normas de direito econômico, de ordem pública e, por isso mesmo, de aplicação imediata, como antes da vigência do Código de Defesa do Consumidor já proclamava o Superior Tribunal de Justiça, entre outros, no REsp n. 2.595-SP (DJ 1\%10/ 1990), julgado em 28.8.90, em cujo voto, como relator, assinalei:

"Orlando Gomes, em obra dedicada ao Direito Econômico, analisando os aspectos jurídicos do dirigismo econômico nos dias atuais, após assinalar que a sanção pela transgressão de norma de ordem pública é a nulidade, afirma:

“Outro princípio que sofre alteração frente à ordem pública dirigista é o da intangibilidade dos contratos. Sempre que uma nova lei é editada nesse domínio, o conteúdo dos contratos que atinge tem de se adaptar às suas inovações. Semelhante adaptaçáo verifica-se por força de aplicação imediata das leis desse teor, sustentada como prática necessária à funcionalidade da legislação econômica dirigista.

Derroga-se com o princípio da aplicação imediata a regra clássica do direito intertemporal que resguarda os contratos de qualquer intervenção legislativa decorrente de lei posterior à sua conclusão"("Direito Econômico", Saraiva, 1977, p. 59).

${ }^{4}$ Op. cit., pp. 10-11. 
Atento à essa qualidade das normas de direito econômico, que se revestem do atributo de normas de ordem pública, esta Corte vem prestigiando a aplicação imediata de tais normas, atingindo contratos em curso".

Posteriormente, a mesma Corte veio reconhecer esse caráter de ordem pública das normas do Código de Defesa do Consumidor, ao afastar, por exemplo, a cláusula contratual de eleição de foro (Conflitos de Competência n. 19.105-MS, DJ 15/3/1999, e n. 32.868-SC, DJ 11/3/2002). Estes acórdãos receberam as seguintes ementas, no pertinente:

. "CONFLITO DE COMPETÊNCIA. CLÁUSULA ELETIVA DE FORO LANÇADA EM CONTRATO DE ADESÃO. NULIDADE COM BASE NA DIFICULDADE DE ACESSO AO JUDICIÁRIO COM PREJUÍZO À AMPLA DEFESA DO RÉU. CARÁTER DE ORDEM PÚBLICA DA NORMA. CÓDIGO DE DEFESA DO CONSUMIDOR. INAPLICABILIDADE DO ENUNCIADO NN 33 DA SÚMULA/STJ.

- Tratando-se de contrato de adesão, a declaração de nulidade da cláusula eletiva, ao fundamento de que estaria ela a dificultar o acesso do réu ao Judiciário, com prejuízo para a sua ampla defesa, torna absoluta a competência do foro do domicílio do réu, afastando a incidência do enunciado n⿳o 33 da Súmula/STJ".

. “COMPETÊNCLA. CONFLITO. FORO DE ELEIÇÃO. CÓDIGO DE DEFESA DO CONSUMIDOR. BANCO. CONTRATO DE ABERTURA DE CRÉDITOEM CONTA ESPECIAL.

- O Código de Defesa do Consumidor orienta a fixação da competência segundo o interesse público e na esteira do que determinam os princípios constitucionais do acesso à Justiça, do contraditório, ampla defesa e igualdade das partes.

- Prestadoras de serviços, as instituições financeiras sujeitam-se à orientação consumerista.

- É nula a cláusula de eleição de foro inserida em contrato de adesão quando gerar maior ônus para a parte hipossuficiente defender-se ou invocar a jurisdição, propondo a ação de consumo em local distante daquele em que reside.

- Conflito conhecido para declarar a competência do Juízo de Direito da 2 ${ }^{\mathrm{a}}$ Vara Cível da Comarca de Canoas".

Oadvento do Código de Defesa do Consumidor contribuiu para acelerar e acentuar o processo de reforma que perpassa os ramos do direito, principalmente o civil, o comercial e o processual. Aliás, o Direito do Consumidor constitui-se em expressivo passo rumoà prevalência dos interesses sociais sobre os meramente individuais. A respeito, já lecionava DARCY BESSONE, nas décadas de 50/60: 
"Tornou-se evidente que é necessário criar um sistema de defesas e garantias, para impedir que os fracos sejam espoliados pelos fortes, assim como para assegurar o predomínio dos interesses sociais sobre os individuais.

Todos, diz RIPERT, apelam para o Estado, exigindo-lhe a ordem econômica. Premido por tão urgentes solicitações, o Estado passa a dirigir o contrato, não tanto segundo a vontade comum e provável dos contratantes, mas atentando, sobretudo, nas necessidades gerais da sociedade. Legisla em nome da ordem pública, cuja noção se alarga e enriquece. A lei deixa de ser a regra abstrata e permanente, para se tornar um regulamento temporário e detalhado.

[...]

Os princípios tradicionais, individualistas e severos, sofrem freqüentes derrogações, em proveito da Justiça contratual e da interdependência das relaçóes entre os homens" (Do contrato, $1^{\underline{a}}$ ed., Rio de Janeiro: Forense, 1960, n. 20, pp. 52-53).

A propósito, no âmbito do direito privado, no Brasil editou-se um novo Código Civil (ainda em vacatio legis), para substituir o anterior, de 1916, buscando a disciplina das obrigações e dos contratos, assim como o direito societário, nos moldes da emergente sociedade de consumo, refletindo "uma mudança de paradigmas que atribui ao moderno direito civil uma tônica social, orientada pela necessidade de realização da justiça concreta e pautada na chamada ética da situaçâo". Depois de quase três décadas de discussão e debates, finalmente se votou e sancionou o novo diploma civil, não obstante a sua desatualização em diversos pontos, sobretudo em relação ao Direito de Família, onde as alterações estão muito aquém das profundas inovações introduzidas na Constituição de 1988, esperando-se agora que, ainda no período da vacatio legis, ou em futuro próximo, advenham mudanças legislativas a atualizar o novo texto editado, compatibilizando-o com as diretrizes constitucionais e com a arejada e renovadora jurisprudência que a esta prontamente se incorporou ${ }^{5}$ Ao escrever sobre a fisionomia do novo Código Civil brasileiro, destaquei:

"Três princípios foram confessadamente adotados pela Comissão de 1969: da socialidade, da operalidade e da eticidade.

${ }^{5}$ O legislador de 2001, por outro lado, introduziu também alteraçōes na própria estrutura do novo Código, dividindo-o em duas partes: uma geral, onde dispõe sobre as pessoas, os bens e os fatos jurídicos; e outra, especial, a tratar, pela ordem, em cinco livros, do Direito das Obrigações(unificado), do Direito de Empresa, do Direito das Coisas, do Direito de Família e do Direito das Sucessões. Em síntese, a par de um sem número de inovações, muitas das quais de grande relevo para a ciência jurídica e para a sociedade brasileira dos nossos dias, e sem embargo das múltiplas deficiências que o texto contém, e que todos esperamos sejam corrigidas legislativamente ainda antes da sua entrada em vigência, certo é que estamos a ingressar em uma nova etapa do Direito Privado brasileiro, com novas regras e a correção de muitas carências acumuladas ao longo do tempo, com a renovação de conceitos e princípios e a esperança de dias melhores, nos quais tenham maior proteção os direitos do cidadão e da pessoa humana" ("O novo Código Civil", ed. América Jurídica, Rio, 2002). 
Pelo primeiro, busca-se fazer prevalecer os valores sociais e coletivos sobre os individuais, dando à nova codificação um perfil bem diferente do anterior, moldado para uma sociedade então predominantemente rural.

Pelo segundo, procura-se dar exeqüibilidade, realização, efetividade, enfim, às normas civis materiais, afastando o culto à forma e ao academicismo, ao fundamento de que não se deve tornar complexo o que deve ser simples e objetivo. Neste sentido, para exemplificar, o tratamento dado à distinção entre prescrição e decadência, elencados os casos daquela na parte geral e acopladas as normas da segunda aos respectivos preceitos.

Pelo princípio da eticidade, por seu turno, o novo Código dá especial ênfase a valores aos quais o Código de 1916 não deu relevo. O novo Código prioriza os valores da pessoa humana sobre o normativismo técnico-jurídico, valorizando a boa-fé, a eqüidade, a justa causa e outros critérios, ampliando a atuação do julgador, conferindo-lhe maior poder para realizar, no caso concreto, a solução mais justa e eqüitativa. Cuida-se aí, sem dúvida, do ponto mais alto do novo estatuto civil.

O Direito Comercial igualmente vem tomando ares de vanguarda ao ampliar os debates sobre as sociedades anônimas e a lei de falências, agora inspirada no soerguimento das empresas e não mais no encerramento definitivo de suas atividades.

Acerca dessa postura do direito privado e da atualidade do Direito do Consumidor, confira-se o REsp n. 63.981-SP (DJ 20/11/2000), de que fui relator, com esta ementa:

"DIREITO DO CONSUMIDOR. FILMADORA ADQUIRIDA NO EXTERIOR. DEFEITO DA MERCADORIA. RESPONSABILIDADEDA EMPRESA NACIONAL DA MESMA MARCA ("PANASONIC"). ECONOMIA GLOBALIZADA. PROPAGANDA. PROTEÇÃO AO CONSUMIDOR. PECULIARIDADES DA ESPÉCIE. SITUAÇÕES A PONDERAR NOS CASOS CONCRETOS. NULIDADE DO ACÓRDĀOESTADUAL REJEITADA, PORQUE SUFICIENTEMENTE FUNDAMENTADO. RECURSO CONHECIDOEPROVIDO NO MÉRITO, POR MAIORIA.

I - Se a economia globalizada não mais tem fronteiras rígidas e estimula e favorece a livre concorrência, imprescindível que as leis de proteção ao consumidor ganhem maior expressão em sua exegese, na busca do equilíbrio que deve reger as relações jurídicas, dimensionando-se, inclusive, o fator risco, inerente à competitividade do comércio e dos negócios mercantis, sobretudo quando em escala internacional, em que presentes empresas poderosas, multinacionais, com filiais em vários países, sem falar nas vendas hoje efetuadas pelo processo tecnológico da informática e no forte mercado consumidor que representa o nosso País.

II - O mercado consumidor, não há como negar, vê-se hoje "bombardeado" diuturnamente por intensa e hábil propaganda, a induzir a aquisição de produtos, 
notadamente os sofisticados de procedência estrangeira, levando em linha de conta diversos fatores, dentre os quais, e com relevo, a respeitabilidade da marca.

III - Se empresas nacionais se beneficiam de marcas mundialmente conhecidas, incumbe-lhes responder também pelas deficiências dos produtos que anunciam e comercializam, não sendo razoável destinar-se ao consumidor as conseqüências negativas dos negócios envolvendo objetos defeituosos.

IV - Impõe-se, no entanto, nos casos concretos, ponderar as situações existentes.

V - Rejeita-se a nulidade argüida quando sem lastro na lei ou nos autos".

A referida jurisprudência brasileira, de sua vez, tem se manifestado em um sem número de variados casos, a exemplo dos relacionados a seguir, de aplicação no campo do direito material:

Cláusula de limitação de tempo de internação (plano de saúde)

- REspn. 251.024-SP (DJ 4/2/2002), 2ª Seção

"DIREITO CIVILE DO CONSUMIDOR. PLANO DE SAÚDE. LIMITAÇÃO TEMPORAL DE INTERNAÇÃO. CLÁUSULA ABUSIVA. CÓDIGO DE DEFESA DO CONSUMIDOR, ART. 51-IV. UNIFORMIZAÇÃO INTERPRETATIVA. PREQUESTIONAMENTO IMPLÍCITO. RECURSO CONHECIDOE PROVIDO.

I - É abusiva, nos termos da lei (CDC, art. 51-IV), a cláusula prevista em contrato de seguro-saúde que limita o tempo de internação do segurado.

II - Tem-se por abusiva a cláusula, no caso, notadamente em face da impossibilidade de previsão do tempo da cura, da irrazoabilidade da suspensão do tratamento indispensável, da vedação de restringir-se em contrato direitos fundamentais e da regra de sobredireito, contida no art. 5 da Lei de Introdução ao Código Civil, segundo a qual, na aplicação da lei, o juiz deve atender aos fins sociais a que ela se dirige a às exigências do bem comum.

III - Desde que a tese jurídica tenha sido apreciada e decidida, a

circunstância de não ter constado do acórdão impugnado referência ao dispositivo legal não é obstáculo ao conhecimento do recurso especial”.

Cláusula dúbia em contrato de adesão

- REspn. 311.509-SP (DJ 25/6/2001)

"DIREITO CIVIL. CONTRATO DE SEGURO-SAÚDE. TRANSPLANTE. COBERTURA DO TRATAMENTO. CLÁUSULA DÚBIA E MAL REDIGIDA. INTERPRETAÇÃO FAVORÁVEL AO CONSUMIDOR. ART. 54, § 4º, CDC. RECURSOESPECIAL. SÚMULA/ST], ENUNCIADO 5. PRECEDENTES. RECURSO NÃO-CONHECIDO. 
I - Cuidando-se de interpretação de contrato de assistência médico-hospitalar, sobre a cobertura ou não de determinado tratamento, tem-se o reexame de cláusula contratual como procedimento defeso no âmbito desta Corte, a teor de seu verbete sumular $\mathrm{n}^{\mathrm{o}} 5$.

II - Acolhida a premissa de que a cláusula excludente seria dúbia e de duvidosa clareza, sua interpretação deve favorecer o segurado, nos termos do art. $54, \S 4^{\circ}$ do Código de Defesa do Consumidor. Com efeito, nos contratos de adesão, as cláusulas limitativas ao direito do consumidor contratante deverão ser redigidas com clareza e destaque, para que não fujam de sua percepção leiga".

Perda das parcelas pagas em compromisso de compra e venda

- REspn. 158.193-AM (DJ 23/10/2000)

1 - É nula a cláusula que estabelece a perda integral das parcelas pagas em contrato de promessa de compra e venda de imóvel, pelo inadimplente, consoante o artigo $53 \mathrm{da}$ Lei no 8.078/90 (Código Brasileiro de Defesa do Consumidor).

Contratos de arrendamento mercantil (leasing)

-REsp n. 248424-RS (DJ 5/2/2001)

“4. O Código de Defesa do Consumidor aplica-se aos contratos de arrendamento mercantil".

Extravio de mercadoria em transporte aéreo

- REsp n. 257.298-SP (DJ 11/6/2001)

"RESPONSABILIDADE CIVIL. AÇÃO REGRESSIVA. TRANSPORTE AÉREO. EXTRAVIO DE MERCADORIA. INAPLICABILIDADE DA CONVENÇÃO DE VARSÓVIA. RELAÇÃO DE CONSUMO. INCIDÊNCIA DO CÓDIGO DE DEFESA DO CONSUMIDOR. INDENIZAÇÃO AMPLA. ORIENTAÇÃO DA TRIBUNAL. RECURSO PROVIDO.

- Nos casos de extravio de mercadoria ocorrido durante o transporte aéreo, há relação de consumo entre as partes, devendo a reparação, assim, ser integral, nos termos do Código de Defesa do Consumidor, e não mais limitada pela legislação especial”.

- REspn. 156.240-SP (DJ 12/2/2001) 
"RESPONSABILIDADE CIVIL. TRANSPORTE AÉREO. EXTRAVIODA BAGAGEM.DANO MATERIAL. DANO MORAL.

- A indenização pelos danos material e moral decorrentes do extravio de bagagem em viagem aérea doméstica não está limitada à tarifa prevista no Código Brasileiro de Aeronáutica, revogado, nessa parte, pelo Código de Defesa do Consumidor”.

Atraso de vôo em viagem internacional

- REsp n. 235.678-SP (DJ 14/2/2000)

“TRANSPORTE AÉREO. ATRASO. VIAGEM INTERNACIONAL. CONVENÇÃO DE VARSÓVIA. DANO MORAL. CÓDIGO DE DEFESA DO CONSUMUDOR.

- O dano moral decorrente de atraso em viagem internacional tem sua indenização calculada de acordo com o CDC'.

Serviço de entrega rápida

- REsp n. 196.031-MG (DJ 11/6/2001)

"DIREITODO CONSUMIDOR. LEI № 8.078/90 E LEINำ 7565/86. RELAÇÃO DE CONSUMO. INCIDÊNCIA DA PRIMEIRA. SERVIÇO DE ENTREGA RÁPIDA. ENTREGA NÃO EFETUADA NO PRAZO CONTRATADO. DANO MATERIAL. INDENIZAÇÃONÃOTARIFADA.

I - Não prevalecem as disposições do Código Brasileiro de Aeronáutica que conflitem com o Código de Defesa do Consumidor.

II - As disposiçōes do Código de Defesa do Consumidor incidem sobre a generalidade das relaçōes de consumo, inclusive as integradas por empresas aéreas.

III-Quando o fornecedor faz constar de oferta ou mensagem publicitária a notável pontualidade e eficiência de seus serviços de entrega, assume os eventuais riscos de sua atividade, inclusive o chamado risco aéreo, com cuja conseqüência não deve arcar o consumidor".

Fabricante de veículo automotor

-REspn. 195.659-SP (DJ 12/6/2000)

“CÓDIGO DE DEFESA DO CONSUMIDOR. COMPRA DE VEÍCULO NOVO COM DEFEITO DE FÁBRICA. RESPONSABILIDADE DOFABRICANTE. 
1. Comprado veículo novo com defeito de fábrica, é responsabilidade do fabricante entregar outro do mesmo modelo, a teor do art. $18, \S 1^{\circ}$, do Código de Defesa do Consumidor".

Fornecimento de água

- REsp n. 263.229-SP (DJ9/4/2001)

"ADMINISTRATIVO. EMPRESA CONCESSIONÁRIA DE FORNECIMENTO DE ÁGUA. RELAÇÃO DE CONSUMO. APLICAÇÃO DOS ARTS. 2 E42, PARÁGRAFO ÚNICO, DO CÓDIGO DE DEFESA DO CONSUMMOR.

1. Há relação de consumo no fornecimento de água por entidade concessionária desse serviço público a empresa que comercializa com pescados.

2. A empresa utiliza o produto como consumidora final.

3. Conceituação de relação de consumo assentada pelo art. $2^{\circ}$, o

Código de Defesa do Consumidor.

4. Tarifas cobradas a mais. Devolução em dobro. Aplicação do art. 42, parágrafo único, do Código de Defesa do Consumidor.

5. Recurso provido".

Fornecimento de energia elétrica

- Ag/REsp n. 298.017-MG (DJ 27/8/2001)

"ADMINISTRATIVO. AGRAVO REGIMENTAL. RECURSO ESPECIAL. ENERGIA ELÉTRICA. SERVIÇO PÚBLICO ESSENCIAL. CORTE DE FORNECIMENTO. CONSUMIDOR INADIMPLENTE. IMPOSSIBILIDADE.

- Esta Corte vem reconhecendo ao consumidor o direito da utilização dos serviços públicos essenciais ao seu cotidiano, como o fornecimento de energia elétrica, em razão do princípio da continuidade (CDC, art. 22).

- O corte de energia, utilizado pela Companhia para obrigar o usuário ao pagamento de tarifa em atraso, extrapola os limites da legalidade, existindo outros meios para buscar o adimplemento do débito".

Atualmente, depois de o Superior Tribunal de Justiça admitir a aplicação do CDC às operações bancárias e até mesmo às financeiras, ${ }^{6}$ a Suprema Corte está a debater a constitucionalidade ou não do Código de Defesa do Consumidor em relação à limitação dos juros bancários. É que a Constituição brasileira remete a regulação do sistema

${ }^{6}$ Entre outros, o $\mathrm{Ag} / \mathrm{Ag}$ n. 296.516-SP (DJ 5/2/2001). 
financeiro nacional à lei complementar, abrindo espaço para a discussão sobre a pertinência de o conceito de serviço, expresso no art. $3^{\circ}, \S 2^{\circ}, \mathrm{CDC}$, incluir as atividades "de natureza bancária, financeira, de crédito e securitária".

Outras situações, evidentemente, estão a exigir maior elaboração doutrinária e jurisprudencial, não só pela novidade do Direito do Consumidor nos ordenamentos normativos como também pela complexidade das relaçōes econômicas na sociedade recente. A própria noção de consumidor enseja controvérsias ainda por descortinar: $o$ art. $2^{\circ}$ o define como "toda pessoa física ou jurídica que adquire ou utiliza produto ou serviço como destinatário final", equiparando a consumidor "a coletividade de pessoas, ainda que indetermináveis, que haja intervindo nas relaçóes de consumo". No ponto, o Superior Tribunal de Justiça considerou inaplicável o CDC em alguns casos, como exemplifica o REsp n. 218.505-MG (DJ 14/2/2000), de cuja ementa se colhe:

\section{“MÚTUO. REDUÇÃO DA MULTA CONTRATUAL DE 10\% PARA 2\%. INEXISTÊNCIA NO CASO DE RELAÇÃO DE CONSUMO. \\ - Tratando-se de financiamento obtido por empresário, destinado precipuamente} a incrementar a sua atividade negocial, não se podendo qualificá-lo, portanto, como destinatário final, inexistente é a pretendida relação de consumo. Inaplicação no caso do Código de Defesa do Consumidor".

Entretanto, a qualificação de destinatário final nem sempre é suficiente para abranger todos os casos na cadeia das relações jurídico-econômicas. É o que se observa, por exemplo, na relação entre o taxista que adquire o automóvel para utilizá-lo em sua atividade lucrativa, como instrumento de trabalho, e o fabricante ou fornecedor. Em caso de defeito do produto, seria questionável a inclusão do comprador entre os consumidores, porquanto não propriamente destinatário final do veículo. De outro lado, existe a relação entre uma fábrica de automóveis e seus fornecedores de peças, ambos de porte econômico elevado. A diferença que se evidencia entre um caso e outro não se situa no destino final do produto, mas sim na disparidade econômica entre as partes na relação jurídica, ou, em outras palavras, a hipossuficiência ou a vulnerabilidade de um lado em relação ao outro.

Nesta seara, a jurisprudência reconheceu a incidência do CDC para o produtor rural que comprou adubo para sua atividade produtiva:

\section{$\cdot$ REsp n. 208.793-MT (DJ 1\%/8/2000)}

“1. A expressão 'destinatário final', constante da parte final do art. $2^{2}$ do Código de Defesa do Consumidor, alcança o produtor agrícola que compra adubo para o preparo do plantio, à medida que o bem adquirido foi utilizado pelo profissional, encerrando-se a cadeia produtiva respectiva, não sendo objeto de transformação ou beneficiamento". 
Trata-se de situações ainda sob meditação da doutrina e da jurisprudência, que não sedimentaram conclusões hábeis a responder à altura ao verdadeiro propósito de proteção do Direito do Consumidor ao economicamente mais vulnerável.

5. A desconsideração da personalidade jurídica

O Código de Defesa do Consumidor positivou a doutrina da desconsideração da personalidade jurídica da sociedade, proclamando o seu art. 28 que poderá ser desconsiderada também "a pessoa jurídica sempre que sua personalidade for, de alguma forma, obstáculo ao ressarcimento de prejuízos causados aos consumidores” ( $\$ 5^{\circ}$ ) .

Neste ponto, o Superior Tribunal de Justiça, na sua condição de Corte Suprema do País como guardião do direito infraconstitucional, tem aplicado o dispositivo em vários de seus julgados, a exemplo dos REsps n. 252.759-SP (DJ 27/11/2000) e 63.652-SP (DJ 21/8/2000), das Turmas Especializadas em Direito Privado, com estas ementas:

\section{"DOUTRINA DA DESCONSIDERAÇÃO DA PERSONALIDADE JURÍDICA. ART. 28 DO CÓDIGO DE DEFESA DO CONSUMIDOR. PRECEDENTES.}

1. Não desqualificada a relação de consumo, possível a desconsideração da personalidade jurídica, provada nas instâncias ordinárias a existência de ato fraudulento e o desvio das finalidades da empresa, ainda mais quando presente a participação direta do sócio, em proveito próprio".

"FALÊNCIA. DESCONSIDERAÇÃO DA PERSONALIDADE JURÍDICA. DUAS RAZÕES SOCIAIS, MAS UMA SÓ PESSOA JURÍDICA. QUEBRA DECRETADA DE AMBAS.

$[\ldots]$

- O juiz pode julgar ineficaz a personificação societária, sempre que for usada com abuso de direito, para fraudar a lei ou prejudicar terceiros".

\section{As ações coletivas e a defesa do consumidor em juízo}

O título II do Código do Consumidor ocupa-se de importante parte a respeito da proteção ao consumidor, ao dispor sobre a sua defesa em juízo.

Nesse título, a Lei no 8.078/90 buscou abranger as atividades desenvolvidas pelo consumidor em juízo, na posição de autor, réu ou eventual beneficiário de ações coletivas ajuizadas por pessoas especialmente legitimadas.

As ações coletivas, que no Brasil ganharam excepcional relevo com a edição da Lei no 7.347, de 24.7.1985, recebeu expressão ainda maior com o advento do Código do Consumidor.

Como assinalei em outra oportunidade, protegendo interesses de consideráveis parcelas da comunidade que se viam frustradas na defesa de seus direitos, sem o devido 
amparo legal, a Lei $\mathrm{n}^{\mathrm{o}} \mathbf{7 . 3 4 7}$, de 24-7-1985, além de tornar realidade o princípio constitucional de acesso à tutela jurisdicional do Estado, representa significativa evolução no sentido da superação do modelo tradicional do processo civil, adequando-oà sociedade dos nossos dias, não mais de características individualistas, mas predominantemente de massa, voltada para o interesse coletivo.

Prevista originariamente, no projeto de 1984, para preservar o meio ambiente e bens ou valores artísticos, estéticos, históricos, turísticos e paisagísticos, a "açāo civil pública", ao ser instituída, se viu também destinada à defesa do consumidor, tendo, inadvertidamente, mantido o qualificativo "pública", que, diga-se de passagem, não lhe assenta em rigor científico.

A "ação civil pública" constitui, além de inegável progresso jurídico, relevante instrumento político, na medida em que, preservando bens e valores caros a segmentos significativos da coletividade, protege, ampara e defende a própria sociedade.

Na esteira dessa Lei 7.347/85 surgiu, em sua parte processual, como ação coletiva, o Código de Defesa do Consumidor (Lei no 8.078/90), tendo o legislador, inteligentemente, ainda feito a interação desses dois diplomas, dispondo em ambos, que neles sejam aplicadas, no que couber, as normas do outro.

Destarte, tanto em uma como em outra dessas duas leis, na parte processual o foco se guiou para o acesso à Justiça.

Em se tratando do consumidor, no entanto, as normas processuais identificam-se nas ações individuais e nas coletivas.

Nas primeiras, o CDC contempla:

a) a possibilidade de fixação da competência pelo domicílio do consumidor autor nas açōes de responsabilidade civil do fornecedor de produtos e serviços (art. 101, I);

b) a inadmissibilidade da denunciação da lide nas ações de regresso intentadas pelo fabricante, construtor, fornecedor, produtor, importador ou o comerciante que tenha pago o prejuízo ao consumidor prejudicado (art. 88);

c) a possibilidade de chamamento ao processo especificamente previsto para $o$ segurador da responsabilidade (art. 101, II) e diverso do instituto já definido no Código de Processo Civil;

d) a reafirmação do direito constitucional subjetivo de ação ao estabelecer que, "para a defesa dos direitos e interesses protegidos por este Código são admissíveis todas as espécies de ações capazes de propiciar sua adequada e efetiva tutela" (art. 83);

e) a tutela específica das obrigações de fazer e não-fazer (art. 84), mais de quatro anos antes de ser introduzida no Código de Processo Civil, permitindo que ojuiz determine "providências que assegurem o resultado prático equivalente ao do adimplemento";

f) a ampliação da extensão subjetiva da coisa julgada nas açóes coletivas, tornandoa erga omnes ou ultra partes, conforme se trate de interesses difusos, coletivos ou individuais homogêneos (art. 103).

Além dessas, a inversão do ônus da prova, a implantação de Juizados Especiais de Pequenas Causas e Varas Especializadas para a solução de litígios de consumo e a assistência 
jurídica integral e gratuita para o consumidor carente vêm ao encontro do propósito maior que inspirou o Código, o acesso à Justiça.

No campo das ações coletivas, todavia, o Direito do Consumidor no Brasil arrimouse em dois pilares: ao positivar as categorias de interesses difusos, coletivos e individuais homogêneos e ao ampliar a legitimação ativa para a defesa dos consumidores em juízo.

O art. 81, parágrafo único, do Código de Defesa do Consumidor assim dispóe:

“Art. 81. A defesa dos interesses e direitos dos consumidores e das vítimas poderá ser exercida em juízo individualmente, ou a título coletivo.

Parágrafo único. A defesa coletiva será exercida quando se tratar de:

I - interesses ou direitos difusos, assim entendidos, para efeitos deste Código, os transindividuais, de natureza indivisível, de que sejam titulares pessoas indeterminadas e ligadas por circunstâncias de fato;

II - interesses ou direitos coletivos, assim entendidos, para efeitos deste código, os transindividuais, de natureza indivisível de que seja titular grupo, categoria ou classe de pessoas ligadas entre si ou com a parte contrária por uma relação jurídica base;

III - interesses ou direitos individuais homogêneos, assim entendidos os decorrentes de origem comum".

Exemplificando, no primeiro grupo estão os atingidos por propaganda enganosa $e$ por produtos nocivos. No segundo, contribuintes ante um mesmo tributo, as associaçōes de pais de alunos e os sindicatos. No terceiro grupo, os alcançados por um ato ilícito civil de mesma origem.

Os arts. 91 e segs., por sua vez, disciplinam as ações coletivas para a defesa de interesses individuais homogêneos.

Mais de uma década antes, em 1978, ao tratar da legitimação coletiva, já preconizavam MAURO CAPPELLETTI e BRYANT GARTH algumas soluções para efetivar-se o acesso à Justiça: além da assistência judiciária aos pobres, preocuparam-se com a representação dos interesses difusos, assim entendidos, na expressão desses ilustres mestres, "os interesses coletivos ou grupais". A propósito, sobre a importância do tema para o processo civil, acentuaram:

"Centrando seu foco de preocupação especificamente nos interesses difusos, esta segunda onda de reformas forçou a reflexão sobre noções tradicionais muito básicas do processo civil e sobre o papel dos tribunais. Sem dúvida, uma verdadeira 'revolução' está-se desenvolvendo dentro do processo civil. Vamos examiná-la brevemente, antes de descrever com mais detalhes as principais soluçōes que emergiram.

A concepção tradicional do processo civil não deixava espaço para a proteção dos interesses difusos. $O$ processo era visto apenas como um assunto entre duas partes, que se destinava à solução de uma controvérsia entre essas mesmas partes a respeito de seus próprios interesses individuais. Direitos que pertencessem a um grupo, ao público em geral ou a um 
segmento do público não se enquadravam bem nesse esquema. As regras determinantes da legitimidade, as normas de procedimento e a atuação dos juízes não eram destinadas a facilitar as demandas por interesses difusos intentadas por particulares" (Acesso à Justiça, trad. Ellen Gracie Northfleet. Porto Alegre: Fabris, 1988, pp. 49-50).

Linhas após, acerca da ampliação da legitimação ativa para defender essa categoria dos interesses, expressaram aqueles doutrinadores:

"Em primeiro lugar, com relação à legitimação ativa, as reformas legislativas e importantes decisões dos tribunais estão cada vez mais permitindo que indivíduos ou grupos atuem em representação dos interesses difusos.

Em segundo lugar, a proteção de tais interesses tornou necessária uma transformação do papel do juiz e de conceitos básicos como a 'citação' e o 'direito de ser ouvido'. Uma vez que nem todos os titulares de um direito difuso podem comparecer a juízo - por exemplo, todos os interessados na manutenção da qualidade do ar, numa determinada região-é preciso que haja um 'representante adequado' para agir em benefício da coletividade, mesmo que os membros dela não sejam 'citados' individualmente. Da mesma forma, para ser efetiva, a decisão deve obrigar a todos os membros do grupo, ainda que nem todos tenham tido a oportunidade de ser ouvidos. Dessa maneira, outra noção tradicional, a da coisa julgada, precisa ser modificada, de modo a permitir a proteção judicial efetiva dos interesses difusos.

[...]

A visão individualista do devido processo judicial está cedendo lugar rapidamente, ou melhor, está se fundindo com uma concepção social, coletiva. Apenas tal transformação pode assegurar a realização dos 'direitos públicos' relativos a interesses difusos” (op. cit., pp. 50-51).

CAPPELLETTI, aliás, noutra oportunidade, em conferência pronunciada no Brasil, em Curitiba, em 18/11/1991, como a recordar FrANz KLEIN, alertava para a dimensão social do processo, que devia voltar-se para a ótica dos usuários da prestaçáo jurisdicional do Estado e não se prender apenas aos seus produtores e produtos e às normas (Problemas de reforma do processo civil nas sociedades contemporâneas, Revista de Processo, São Paulo, 65/127).

Sem revolver aqui a evolução histórica dos interesses coletivos e difusos, é pertinente salientar, todavia, que sua inclusão entre os direitos fundamentais advieram dos movimentos sociais das décadas de 1950 e 1960, sobretudo nos Estados Unidos, onde as manifestações das mulheres, dos negros, dos ambientalistas e dos integrantes de parcelas excluídas da proteção estatal culminaram na edição do Civil Rights Act, em 1964, que, combatendo a segregação racial nas escolas, mais tarde propiciaram as políticas de ação afirmativa. ${ }^{7}$

\footnotetext{
7 Por todos, Márcio Flávio Mafra Leal, "Ações coletivas: história, teoria e prática", Sérgio Antônio Fabris, 1998, cap. 7.
} 
Desde então os direitos coletivos e difusos passaram a exigir meios de concretização, que necessariamente dependiam de políticas públicas e mudanças de comportamento das empresas privadas.

Um desses instrumentos de concretização foi a ampliação do rol de pessoas legitimadas para intentar as açōes coletivas, como o Ministério Público, as entidades não-governamentais sem fins lucrativos e o indivíduo, isoladamente ou como cidadão, no caso da ação popular brasileira, ao lado das associaçóes civis, das fundações e os sindicatos, que passaram igualmente a expandir seu poder de atuação conforme sua capacidade de organização na sociedade.

\section{A inversão do ônus da prova}

A par das transformaçōes do Direito Privado, o Direito Público, em especial o processo civil, sofreu mudanças significativas, entre as quais se insere, além de uma nova visão do instituto da res iudicata, a inversão do ônus da prova, quer dizer, é direito básico do consumidor "a facilitação da defesa de seus direitos, inclusive com a inversão do ônus da prova, a seu favor, no processo civil, quando, a critério do juiz, for verossímil a alegação ou quando for ele hipossuficiente, segundo as regras ordinárias de experiência" (art. 6으, VIII).

Na jurisprudência do Superior Tribunal de Justiça, sobre o tema, exemplificam os REsps n. 140.097-SP (DJ 11/9/2000), 81.101-PR (DJ 31/5/1999), 122.505-SP (DJ 24/8/ 1998) e 203.225-MG (j. em 2.4.2002):

- "A regra contida no art. 6\%/VIII do Código de Defesa do Consumidor, que cogita da inversão do ônus da prova, tem a motivação de igualar as partes que ocupam posições não-isonômicas, sendo nitidamente posta a favor do consumidor, cujo acionamento fica a critério do juiz sempre que houver verossimilhança na alegação ou quando o consumidor for hipossuficiente, segundo as regras ordinárias da experiência, por isso mesmo que exige do magistrado, quando de sua aplicação, uma aguçada sensibilidade quanto à realidade mais ampla onde está contido o objeto da prova cuja inversão vai operar-se. Hipótese em que a ré/recorrente está muito mais apta a provar que a nicotina não causa dependência que a autora/recorrida provar que ela causa".

- “CIVIL E PROCESSUAL - CIRURGIA ESTÉTICA OU PLÁSTICA . OBRIGAÇÃO DE RESULTADO (RESPONSABILIDADE CONTRATUAL OU OBJETIVA) - INDENIZAÇÃO - INVERSÃO DO ÔNUS DA PROVA.

I - Contratada a realização da cirurgia estética embelezadora, o cirurgião assume obrigação de resultado (responsabilidade contratual ou objetiva), devendo indenizar pelo não cumprimento da mesma, decorrente de eventual deformidade ou de alguma irregularidade.

II - Cabível a inversão do ônus da prova. 
III - Recurso conhecido e provido".

\section{."RESPONSABILIDADE CIVIL. CIRURGIÃO-DENTISTA. INVERSÃODO ÔNUS DA PROVA. RESPONSABILIDADE DOS PROFISSIONAIS LIBERAIS.}

1. No sistema do Código de Defesa do Consumidor a "responsabilidade pessoal dos profissionais liberais será apurada mediante a verificação de culpa” (art. 14, § 4%).

2. A chamada inversão do ônus da prova, no Código de Defesa do Consumidor, está no contexto da facilitação da defesa dos direitos do consumidor, ficando subordinada ao "critério do juiz, quando for verossímil a alegação ou quando for ele hipossuficiente, segundo as regras ordinárias de experiências" (art. 6ํ, VIII). Isso quer dizer que não é automática a inversâo do ônus da prova. Ela depende de circunstâncias concretas que serão apuradas pelo juiz no contexto da "facilitação da defesa" dos direitos do consumidor. E essas circunstâncias concretas, nesse caso, não foram consideradas presentes pelas instâncias ordinárias.

3. Recurso especial não conhecido".

• "Não há vício em acolher-se a inversão do ônus da prova por ocasião da decisão, quando já produzida a prova”.

É próprio ressaltar que o ônus da prova segue, no Brasil - e continua a seguir -, a regra geral de incumbir a quem alega o fato constitutivo do seu direito, como expressa o art. 333 do Código de Processo Civil de 1973. O Código de Defesa do Consumidor não derrogou essa regra geral, porém flexibilizou sua aplicação ao permitir ao juiz inverter o ônus em duas situações: tratar-se de alegação semelhante à verdade, provavelmente verdadeira, e estar o consumidor em posição hipossuficiente na relação jurídica de consumo estabelecida em cada caso levado a exame do Judiciário. As duas premissas para a inversão do ônus da prova, como se vê no art. $6^{\circ}, \mathrm{CDC}$, devem fundar-se na experiência comum, no senso de julgamento do magistrado.

\section{A legitimação ativa nas ações coletivas}

Afastando as limitaçóes do art. $6^{\circ}$ do Código de Processo Civil, segundo o qual "ninguém poderá pleitear, em nome próprio, direito alheio, salvo quando autorizado por lei”, nas açōes coletivas o legislador ordinário brasileiro inovou de forma louvável em se tratando de legitimação ativa, o que também ocorreu no texto constitucional, dando especial relevo ao Ministério Público, quer como custos legis, quer como parte legitimada, o que, ressalvados alguns excessos, tem contribuído em muito para a efetividade dos processos coletivos. Aliás, a missão institucional do Ministério Público tem se sobrelevado na solidificação da democracia, mediante a garantia dos instrumentos necessários e efetivos de cidadania. A respeito, a jurisprudência tem reconhecido o mérito da Instituição, como 
se extrai, entre outros, do REsp n. 34.155-MG (DJ 11/1/1996), por mim relatado e assim ementado:

"PROCESSUAL CIVIL. AÇÃO CIVIL PÚBLICA. MENSALIDADES ESCOLARES. MINISTÉRIO PÚBLICO. INTERESSE COLETIVO. LEGITIMAÇÃO ATIVA. DOUTRINA. PRECEDENTES. RECURSOPROVIDO.

I - Sob o enfoque de uma interpretação teleológica, tem o Ministério Público, em sua destinação institucional, legitimidade ativa para a ação civil pública versando mensalidades escolares, uma vez caracterizados na espécie o interesse coletivo e a relevância social.

II - Na sociedade contemporânea, marcadamente de massa, e sob os influxos de uma nova atmosfera cultural, o processo civil, vinculado estreitamente aos princípios constitucionais e dando-lhes efetividade, encontra no Ministério Público uma instituição de extraordinário valor na defesa da cidadania".

Em várias outras hipóteses, o Ministério Público tem reconhecida legitimidade para atuar em defesa dos consumidores, como mostram estes precedentes do Superior Tribunal de Justiça:

Parcelamento do solo

$\cdot R E s p$ 174.308-SP, DJ 25/2/2002

"ADMINISTRATIVO. PROCESSUAL CIVIL. AÇÃO CIVIL PÚBLICA (LEI 7.347/85). INTERESSES INDIVIDUAIS HOMOGÊNEOS. LEGITIMAÇÃO ATIVA AD CAUSAM DO MINISTÉRIO PÚBLICO.

1. O Ministério Público tem legitimação ativa ad causam para promover ação civil pública destinada à defesa dos interesses difusos e coletivos, incluindo aqueles decorrentes de projetos referentes ao parcelamento de solo urbano.

2.Precedentes jurisprudenciais"

Plano de saúde

- REsp 177.965-PR, DJ 23/8/1999

“AÇÃO CIVIL PÚBLICA. AÇÃO COLETIVA. MINISTÉRIO PÚBLICO. LEGITIMIDADE. INTERESSES INDIVIDUAIS HOMOGÊNEOS. PLANO DE SAÚDE. REAJUSTE DA MENSALDADE. UNIMED.

- O Ministério Público tem legitimidade para promover ação coletiva em defesa de interesses individuais homogêneos quando existente interesse social compatível com 
a finalidade da instituição. Reajuste de prestações de Plano de Saúde (UNIMED). Art. 82, I, da Lei no 8.078/90 (Código de Defesa do Consumidor). Precedentes.

- Recurso conhecido e provido".

Prêmio de seguro-saúde

$\cdot R E s p 286.732-R J, D J 12 / 11 / 2001$

"RECURSO ESPECIAL. PROCESSUAL CIVIL E CIVIL. MINISTÉRIO PÚBLICO. LEGITIMIDADE. AÇÃO CIVIL PÚBLICA. CONTRATOSDE SEGURO. SAÚDE. PRÊMIO. REAJUSTAMENTO DE VALORES. ATO ADMINISTRATIVO. DESCONFORMIDADE COM AS REGRAS PERTINENTES.

- Segundo as áreas de especialização estabelecidas em razão da matéria no Regimento Interno do Superior Tribunal de Justiça compete à Segunda Seção processar e julgar feitos relativos a direito privado em geral.

- O debate sobre a legitimidade do Ministério Público para ajuizar ação civil pública em favor dos consumidores do serviço de saúde prejudicados pela majoração ilegal dos prêmios de seguro-saúde situa-se no campo do Direito Privado.

- É cabível ação civil pública para requerer a suspensão de cobrança a maior de prêmios de seguro-saúde. Em tal caso, o interesse a ser defendido não é de natureza individual, mas de todos os consumidores lesados que pactuaram com as empresas de seguro-saúde.

- O Ministério Público Estadual tem legitimidade para propor a ação porquanto se refere à defesa de interesses coletivos ou individuais homogêneos, em que se configura interesse social relevante, relacionados com o acesso à saúde".

\section{Contrato bancário por adesão}

$\cdot R E s p$ 175.645-RS, DJ 30/4/2001

“AÇÃO CIVIL PÚBLICA. CONTRATOS DE ADESÃO. LEGITIMIDADE DOMINISTÉRIO PÚBLICO.

- OMinistério Público possui legitimidade para promover ação civil pública tendo por objeto cláusulas de contratos bancários de ade'são. Recurso não conhecido".

Ingresso de idosos em estádio de futebol

$\cdot R E s p 242.643-S C, D J 18 / 12 / 2000$ 
“AÇÃO CIVIL PÚBLICA. MINISTÉRIO PÚBLICO. LEGITIMIDADE. INGRESSO GRATUITO DE APOSENTADOS EM ESTÁDIO DE FUTEBOL. LAZER.

- O Ministério Público tem legitimidade para promover ação civil pública em defesa de interesse coletivo dos aposentados que tiveram assegurado por lei estadual o ingresso em estádio de futebol. O lazer do idoso tem relevância social, e o interesse que dele decorre à categoria dos aposentados pode ser defendido em juízo pelo Ministério Público, na ação civil pública.

-Recurso conhecido e provido".

Compra e venda de imóvel por adesão

$\cdot$ EREsp 141491-SC

"PROCESSUAL CIVIL. AÇÃO COLETIVA. CUMULAÇÃO DE DEMANDAS. NULIDADE DE CLÁUSULA DE INSTRUMENTO DE COMPRAE-VENDA DE IMÓVEIS. JUROS. INDENIZAÇÃO DOS CONSUMIDORES QUE JÁ ADERIRAM AOS REFERIDOS CONTRATOS. OBRIGAÇÃODE NÃO-FAZER DA CONSTRUTORA. PROIBIÇÃO DE FAZER CONSTAR NOS CONTRATOS FUTUROS. DIREITOS COLETIVOS, INDIVIDUAIS HOMOGÊNEOS EDIFUSOS. MINISTÉRIO PÚBLICO. LEGITIMIDADE. DOUTRINA. JURISPRUDÊNCIA. RECURSOPROVIDO.

I - O Ministério Público é parte legítima para ajuizar ação coletiva de proteção ao consumidor, em cumulação de demandas, visando: a) a nulidade de cláusula contratual (juros mensais); b) a indenização pelos consumidores que já firmaram os contratos em que constava tal cláusula; c) a obrigação de não mais inseri-la nos contratos futuros, quando presente como de interesse social relevante a aquisição, por grupo de adquirentes, da casa própria que ostentam a condição das chamadas classes média e média baixa.

II - Como já assinalado anteriormente (REsp. 34.155-MG), na sociedade contemporânea, marcadamente de massa, e sob os influxos de uma nova atmosfera cultural, o processo civil, vinculado estreitamente aos princípios constitucionais e dandolhes efetividade, encontra no Ministério Público uma instituição de extraordinário valor na defesa da cidadania.

III - Direitos (ou interesses) difusos e coletivos se caracterizam como direitos transindividuais, de natureza indivisível. Os primeiros dizem respeito a pessoas indeterminadas que se encontram ligadas por circunstâncias de fato; os segundos, a um grupo de pessoas ligadas entre si ou com a parte contrária através de uma única relação jurídica.

IV - Direitos individuais homogêneos são aqueles que têm a mesma origem no tocante aos fatos geradores de tais direitos, origem idêntica essa que recomenda a defesa de todos a um só tempo. 
V - Embargos acolhidos".

Interesses individuais homogêneos

$\cdot R E s p$ 168.859-RJ, DJ 23/8/1999

“AÇÃO CIVIL PÚBLICA. AÇÃO COLETIVA. MINISTÉRIO PÚBLICO. LEGITIMIDADE. INTERESSES INDIVIDUAIS HOMOGÊNEOS. CLÁUSULAS ABUSIVAS.

- O Ministério Público tem legitimidade para promover ação coletiva em defesa de interesses individuais homogêneos quando existente interesse social compatível com a finalidade da instituição.

- Nulidade de cláusulas constantes de contratos de adesão sobre correção monetária de prestaçóes para a aquisição de imóveis, que seriam contrárias à legislação em vigor. Art. 81, parágrafo único III e art. 82, I, da Lei no 8.078/90 (Código de Defesa do Consumidor). Precedentes.

- Recurso conhecido e provido".

Segurados INSS

$\cdot R E s p 211.019-S P, D J 8 / 5 / 2000$

"PROCESSUAL CIVIL. AÇÃO CIVIL PÚBLICA. DIREITOS INDIVIDUAIS HOMOGÊNEOS. INTERESSE PUBLICO. MINISTÉRIO PÚBLICO FEDERAL.

- O Ministério Público possui legitimidade para propor ação coletiva visando proteger o interesse, de todos os segurados que recebiam benefício de prestação continuada do INSS, pertinente ao pagamento dos benefícios sem a devida atualização, o que estaria causando prejuízo grave a todos os beneficiários.

- Sobre as atribuições dos integrantes do Ministério Público, cumpre asseverar que a norma legal abrange toda a amplitude de seus conceitos e interpretá-la com restriçóes seria contrariar os princípios institucionais que regem esse órgão.

- Recurso provido".

Salário mínimo de servidor municipal

$\cdot R E s p$ 95.347-SE, DJ 1\%/2/1999

"PROCESSUAL CIVIL. AÇÃO CIVIL PÚBLICA. DIREITOS E INTERESSES INDIVIDUAIS HOMOGÊNEOS. MINISTÉRIO PÚBLICO. LEGITIMIDADE. RECURSOESPECIAL.

1. Há certos direitos e interesses individuais homogêneos que, quando visualizados em seu conjunto, de forma coletiva e impessoal, passam a representar mais que a soma 
de interesses dos respectivos titulares, mas verdadeiros interesses sociais, sendo cabível sua proteção pela ação civil pública.

2. É o Ministério Público ente legitimado a postular, via ação civil pública, a proteção do direito ao salário-mínimo dos servidores municipais, tendo em vista sua relevância social, o número de pessoas que envolvem a economia processual.

3. Recurso conhecido e provido".

Nulidade de concurso público

- REsp 180.350-SP, DJ9/11/1998

\title{
"PROCESSUAL. LEGITIMDADE. MINISTÉRIO PÚBLICO. AÇÃO CIVIL PÚBLICA. CONCURSO PÚBLICO.
}

- O Ministério Público é legitimado a propor ação civil pública, visandoà decretação de nulidade de concurso público que afrontou os princípios de acessibilidade, legalidade e moralidade.

- Trata-se de interesses transindividuais de categoria ou classe de pessoa e de direitos indivísiveis e indisponíveis, de toda coletividade.

- Recurso improvido".

Em outros casos, contudo, a Corte não admitiu a legitimidade ativa do Ministério Público para defender interesse dos consumidores, porquanto não configurado, no seu entendimento, o interesse difuso ou coletivo. É o que se vê nestes dois julgamentos, relativos à cobrança de tributos e à aposentadoria e pensão de servidores públicos:

Cobrança de tributo

- REsp 175.888-PR, DJ 3/5/1999

\begin{abstract}
"PROCESSUAL CIVIL. AÇÃO CIVIL PÚBLICA PARA DECLARAÇÃODE INCONSTITUCIONALIDADE DE LEI E DEFENDER DIREITOS DIVISÍVEIS. LEGITIMIDADE DO MINISTÉRIO PÚBLICO PARA FIGURAR NO PÓLO ATIVO. EXTINÇÃO DO PROCESSO.
\end{abstract}

- O Ministério Público só tem legitimidade para figurar no pólo ativo de ação civil pública, quando na defesa de interesse difuso ou coletivo, assim entendidos os transindividuais, de natureza indivisível, de que sejam titulares pessoas indeterminadas e ligadas por circunstâncias de fato (art. 81, parágrafo único, incisos I e II da Lei 8.078) de que seja titular grupo, categoria ou classe de pessoas ligadas entre si ou com a parte contrária por uma relação jurídica base.

- O pedido de suspensão de pagamento de tributo e a respectiva repetição de indébito não se insere na categoria de interesses difusos ou coletivos, porquanto, são 
divisíveis e individualizáveis. Interesse coletivo, na dicção da lei, não se confunde com interesse público ou da coletividade, pois, aquele, (interesse público) não entende como sendo uma simples realidade quantitativa, dependente do número de indivíduos que o partilham. O pedido de sustação de pagamento de tributo, cumulado com repetição de indébito, não tem conteúdo de interesse público, a ser protegido pela ação civil pública, que não pode substituir a de repetição de indébito, pois, se cuida de direito individual, determinado, quantificado, eis que, cada contribuinte efetua pagamento de quantia certa, em período considerado. Os contribuintes não são consumidores, não havendo como se vislumbrar sua equiparação aos portadores de direitos difusos ou coletivos (Lei $\mathrm{n}^{\mathrm{o}} \mathbf{7 . 3 4 7}$, art. $1^{\mathrm{o}}$, IV).

- Em se tratando, in casu, de direitos individuais homogêneos, identificáveis e divisíveis, titularidades e quantificáveis, devem ser postulados, na esfera jurisdicional, pelos seus próprios titulares, já que, na sistemática do nosso direito, salvo exceção legal, ninguém poderá pleitear, em nome próprio, direito alheio.

Recurso improvido. Decisão unânime”.

\section{Aposentadoria e pensão de servidor}

\section{- REsp 143.215-PB, DJ 7/12/1998}

“AÇÃO CIVIL PÚBLICA. INTERESSES INDIVIDUAIS DISPONÍVEIS. ILEGITIMIDADE DO MINISTÉRIO PÚBLICO FEDERAL.

- O Ministério Público Federal não possui legitimidade para propor ação civil pública visando à manutenção de aposentadorias e pensões de servidores públicos da Universidade Federal da Paraíba. Tratando-se de direitos individuais disponíveis, os titulares podem deles dispor. Inexistência de violaçáo à Lei Complementar $\mathrm{n}^{\mathrm{O}} 75 / 93$ è Lei $\mathbf{n}^{\mathrm{O}}$ 7.347/85.

- Recurso especial desprovido".

Além do Parquet, as associações de defesa dos consumidores vêm tendo reconhecida legitimidade para atuar ativamente nas açóes coletivas, uma vez presente o interesse difuso e coletivo. A propósito, ilustram os seguintes julgados do Superior Tribunal de Justiça:

$\cdot R E s p$ 157.713-RS, DJ 21/08/2000

"AÇÃO COLETIVA. DIREITOS INDIVIDUAIS HOMOGÊNEOS. ASSOCIAÇÕES. LEGITIMIDADE

- As associaçóes a que se refere o artigo 82, IV do Código de Defesa do Consumidor têm legitimidade para pleitear em juízo em favor de quantos se encontrem na situação alcançada por seus fins institucionais, ainda que não sejam seus associados". 
Empréstimo compulsório sobre combustíveis

$\cdot R E s p$ n. 294.021-PR (DJ 2/4/2001)

“6. A Lei da Ação Civil Pública foi alterada pelo Código de Defesa do Consumidor, restando possibilitado o ajuizamento de ações civis públicas para a defesa também dos chamados "interesses individuais homogêneos", entre os quais se situam os do caso em comento: consumidores de combustíveis (gasolina e álcool) que passaram a pagar, embutido no preço do bem consumido, a exação prevista no Decreto-Lei no 2.288 , de 1986, denominada "empréstimo compulsório sobre o consumo de combustíveis".

7. O argumento de que a extensão de eficácia erga omnes somente é cabível nas hipóteses previstas originalmente na Lei $\mathrm{n} \mathbf{0}$ 7.347/85 cai por terra diante da autorização expressa para interação entre a Lei da Ação Civil Pública e o Código de Defesa do Consumidor (art. 21 da, Lei no 7.347/85, com a redação que lhe foi dada pelo art. 117, da Lei no 8.078/90). Assim, afasta-se a alegação de incompetência do Juízo da 4 a Vara Federal de Curitiba para a concessão de amplitude territorial à sentença, porquanto tal amplitude está prevista no ordenamento jurídico nos arts. 16, da Lei no 7.347/85, e 103, da Lei no 8.078/90, e é efeito da sentença em ação deste gênero.

8. A Lei $\mathrm{n}^{\circ} 7.347 / 85$, em seu art. $5^{\circ}$, autoriza a propositura de ações civis públicas por associações que incluam entre suas finalidades institucionais, a proteção ao meio ambiente, ao consumidor, ao patrimônio artístico, estético, histórico, turístico

e paisagístico, ou a qualquer outro interesse difuso ou coletivo.

9. A Associação Paranaense de Defesa do Consumidor - APADECO - possui, no art. $2^{\circ}$ do seu Estatuto Social, as seguintes finalidades: "art. $2^{\circ}$ - A Associação Paranaense de Defesa do Consumidor - APADECO - tem por finalidade essencial promover a defesa do consumidor, de acordo com as normas do Código de Defesa do Consumidor (CODECON) e legislação correlata, como também dos contribuintes e a quaisquer outras pessoas, relativamente aos danos causados ao meio ambiente e qualquer outro interesse difuso ou coletivo, na forma da Lei de Ação Civil Pública e legislação vigente".

10. O direito em questão é individual, embora homogêneo. São interesses metaindividuais, não são interesses públicos, nem privados: são interesses sociais. $\mathrm{E}$, os interesses individuais, coletivamente tratados, adquirem relevância social, que impõem a sua proteção pela via especial".

Planos de saúde

- REsp 72.994-SP DJ 17/9/2001

"AÇÃO CIVIL PÚBLICA. ENTIDADES DE SAÚDE. AUMENTO DAS PRESTAÇÕES. LEGITIMIDADE ATIVA. 
1. O Instituto Brasileiro de Defesa do Consumidor - IDEC tem legitimidade ativa para ajuizar ação civil pública em defesa dos consumidores de planos de saúde.

2. Antes mesmo do Código de Defesa do Consumidor, o país sempre buscou instrumentos de defesa coletiva dos direitos, ganhando força seja com a Lei $\mathbf{n}^{\circ} 7.347 / 87$ seja alcançando dimensão especial com a disciplina constitucional de 1988. Sedimentados os conceitos centrais, não há razão que afaste o presente feito do caminho da ação civil pública. $\mathrm{O}$ instituto autor é entidade regularmente constituída e tem legitimidade ativa para ajuizar a ação civil pública de responsabilidade por danos patrimoniais causados ao consumidor.

3. Recurso especial conhecido e provido".

Consumidores excluídos de consórcio

$\cdot R E s p 222.569-S P D J 27 / 8 / 2001$

\section{“AÇĀO CIVIL PÚBLICA. CÓDIGO DE DEFESA DO CONSUMIDOR. CONSÓRCIO. ASSOCIAÇÃO. LEGITIMIDADE DE PARTE ATIVA.}

- A associação, que tem por finalidade a defesa do consumidor, pode propor ação coletiva em favor dos participantes, desistentes ou excluídos, de consórcio, visto cuidarse aí de interesses individuais homogêneos".

$\cdot R E s p$ 132.724-RS, DJ 19/2/2001

"PROCESSO CIVIL. LEGITIMIDADE AD CAUSAM.

- Ação coletiva proposta por uma associação em defesa de direito individual homogêneo de consorciados desistentes para obter a devolução atualizada das prestações pagas; sentença de procedência que alcança todos os ex-participantes do consórcio. Recurso especial conhecido e provido".

$\cdot R E S P 132063 / R S, D J 6 / 4 / 1998$

"CODIGO DE DEFESA DO CONSUMIDOR. AÇÃO COLETIVA. LEGITIMIDADE 'AD CAUSAM'. ASSOCIAÇÃO. CONSORCIO.

- A associação que tem por finalidade a defesa do consumidor pode propor ação coletiva em favor dos participantes desistentes de consórcio de veículos, não se exigindo tenha sido instituída para a defesa específica dos interesses de consorciados. Art. 82, IV do CDC.

Recurso conhecido e provido".

Entidade representativa de classe (farmacêuticos) 
“Têm as entidades representativas de classe legitimidade ativa para defender direitos e interesses de seus associados, independentemente de autorização destes.

A associação de farmacêuticos tem legitimidade para impugnar interpretação de preceito contido no Dec. 793/93 que, embora dirigido às drogarias, atinge também as farmácias".

Condomínio em benefício dos condôminos

- REsp 66.565-MG, DJ 24/11/1997

"DIREITOS CIVIL E PROCESSUAL CIVIL. CONDOMINIO. DEFEITOS DE CONSTRUÇÃO. AREA COMUM. LEGITIMIDADE ATIVA. INTERESSES DOS CONDOMINIOS. IRRELEVANCIA. PRESCRIÇÃO. PRAZO. ENUNCIADO N. 194 DA SUMULA/STJ. INTERESSES INDIVIDUAIS HOMOGENEOS. SOLIDEZ E SEGURANÇA DO PREDIO. INTERPRETAÇÃO EXTENSIVA. LEIS 4.591/64 E 8.078/90 (CODIGO DE DEFESA DO CONSUMIDOR). PRECEDENTES. RECURSO DESACOLHIDO.

I- O condomínio tem legitimidade ativa para pleitear reparação de danos por defeitos de construção ocorridos na área comum do edifício, bem como na área individual de cada unidade habitacional, podendo defender tanto os interesses coletivos quanto individuais homogêneos dos moradores".

\section{Conclusão}

Ao focalizar o sistema jurídico brasileiro de defesa do consumidor, buscamos, antes de qualquer outra preocupação, dar as suas diretrizes gerais, a partir do texto constitucional, que lhe deu guarida, a começar por determinar a elaboração de um Código, que, por sua vez, adotou regras de direito material e de direito processual, em ambas as vertentes revolucionando o direito brasileiro.

Quanto às primeiras, ao encontrar vigente no País uma legislação de direito privado ultrapassada, deu a este um novo vigor, chegando mesmo a influenciar na elaboração final do novo Código Civil já aprovado e sancionado, para tanto encontrando a atuação arejada, fecunda e de vanguarda da jurisprudência de ponta, na qual tem tido especial relevo o Superior Tribunal de Justiça, a Corte maior do País na interpretação e aplicação do direito federal infraconstitucional.

Quanto às normas processuais, sua influência se faz sentir sobretudo em termos de coisa julgada, de inversão do ônus da prova e legitimação ad causam, sendo significativa a sua contribuição ao princípio do acesso à tutela jurisdicional, uma das preocupaçóes maiores do processo civil contemporâneo e um dos seus princípios mais nobres. 